\title{
1 Host specificity of Aphelinus species considered for introduction to control Diuraphis noxia
}

2 Keith R. Hopper ${ }^{1}$, Kathryn Lanier ${ }^{1}$, Joshua H. Rhoades ${ }^{1}$, Dominique Coutinot ${ }^{2}$, Guy Mercadier ${ }^{2}$,

3 Nathalie Ramualde ${ }^{2}$, Marie Roche ${ }^{2}$, James B. Woolley ${ }^{3}$, John M. Heraty ${ }^{4}$

$4 \quad{ }^{1}$ USDA-ARS, Beneficial Insect Introductions Research Unit, Newark, Delaware 19736, USA

$5 \quad{ }^{2}$ USDA-ARS, European Biological Control Laboratory, F-34980 Montferrier Sur Lez, France

$6 \quad{ }^{3}$ Department of Entomology, Texas A\&M University, College Station, Texas 77843, USA

$7 \quad{ }^{4}$ Department of Entomology, University of California, Riverside, California 92521, USA

8 *Corresponding author.

$9 \quad$ email: Keith.Hopper@ars.usda.gov

10 phone: $302-731-7330$ ext 238

11 address: USDA-ARS, Beneficial Insect Introductions Research Unit, 501 South Chapel Street,

$12 \quad$ Newark, Delaware 19736, US 


\section{Abstract}

14 Diuraphis noxia, the Russian wheat aphid, has become a major pest of wheat and barley since first 15 being detected in the western USA in 1986. However, it is rarely a pest in Eurasia, its area of origin, 16 and research has shown that natural enemies can limit its abundance there. Among the most important 17 of natural enemies of $D$. noxia in Eurasia are parasitoids in the genus Aphelinus. Here we report 18 results on host specificity of ten populations of seven species from two species complexes in the 19 genus Aphelinus. Host specificity was not related to host plant species or the phylogenetic relatedness

20 of the aphids or the parasitoids. While some species had very broad host ranges and others had

21 intermediate host ranges, Aphelinus hordei had a very narrow host range, being restricted primarily to 22 species in the genus Diuraphis, and especially D. noxia. We also report the results of experiments on 23 the mechanisms of this host specificity. Most of the host specificity of $A$. hordei can be explained by 24 differences in the behavior of females when they encountered different aphid species. Females of $A$. 25 hordei rarely approach, sting, oviposit or host feed on aphids outside the genus Diuraphis, and they 26 oviposit most frequently in D. noxia. From these results, we conclude that $A$. hordei is an excellent 27 candidate for introduction into the USA to control D. noxia.

28 Keywords: biological control, Russian wheat aphid, Aphelinus hordei, Aphelinus varipes complex, 29 Aphelinus asychis complex 


\section{Introduction}

After Diuraphis noxia Kurdjumov (Hemiptera: Aphididae) was detected in the western USA in 1986 (Stoetzel, 1987), it rapidly became a major pest of wheat and barley (Brooks et al., 1994), causing over $\$ 1$ billion in damage and control costs in the first decade after it was found here (Morrison and Peairs, 1998). Wheat varieties resistant to D. noxia began to be used in 1996, and research has revealed multiple genes affecting resistance to D. noxia in wheat (Fazel-Najafabadi et al., 2015) and barley (Dahleen et al., 2015). However, aphid genotypes able to overcome one or more of these resistance genes began appearing by 2003 (Haley et al., 2004), and four virulent biotypes of $D$. noxia have been discovered, some of which have become widespread (Puterka et al., 2015; Randolph et al., 2009). Biological control, particularly in the form of introduced parasitoids that are specific to $D$. noxia, may not only provide direct control of this aphid, but also may slow the spread of virulent biotypes. Parasitoids could reduce the prevalence of virulent biotypes by causing density or frequency dependent mortality.

Diuraphis noxia is seldom a pest in Eurasia, its area of origin, although short-lived outbreaks have been reported (Fernandez et al., 1992; Grossheim, 1914; Tuatay and Remaudière, 1964). Field surveys and exclosure experiments have shown that natural enemies can limit $D$. noxia abundance in Eurasia (Basky and Hopper, 2000; Chen and Hopper, 1997; Hopper et al., 1995), but native natural enemies in the USA have had little impact (Feng et al., 1992; Lajeunesse and Johnson, 1991; Wraight et al., 1993). In Eurasia, parasitoids in the genus Aphelinus are among the most important of natural enemies of D. noxia (De Farias, 1995; Hopper et al., 1998). Aphelinus atriplicis Kurdjumov (Hymenoptera: Aphelinidae) was introduced and established against D. noxia by 1996 (Hopper et al., 1998) [although at the time, it was misidentified as A. albipodus (Heraty et al., 2007)]. This parasitoid has become the most frequently encountered natural enemy of D. noxia (Brewer et al., 2005), being found on 13-16\% of sentinel pots of D. noxia-infested wheat in Colorado, Nebraska, and Wyoming (Noma et al., 2005). Nonetheless, D. noxia remains a pest, and a project was initiated to find additional candidates for introduction against it. To ensure introductions of exotic natural enemies would have minimum impact on non-target species, candidates were screened for host specificity.

The genus Aphelinus comprises >90 species (Hopper et al., 2012; Noyes, 2015; Shirley et al., 2016) that are all koinobiont endoparasitoids of aphids. They are small ( 1 mm long) and weak fliers, searching for hosts and mates primarily while walking (Fauvergue and Hopper, 
2009; Fauvergue et al., 1995). Aphelinus females prefer $2-4^{\text {th }}$ instar aphids for oviposition, but will oviposit in all stages, including alate adults (Rohne, 2002). At $20^{\circ} \mathrm{C}$, wasp progeny develop from an oviposited egg to pupation in about two weeks. At the third instar of the wasp, Aphelinus kill their hosts but leave the aphid exoskeleton intact, causing it to harden and turn black in a process called mummification (Christiansen-Weniger, 1994). Adults emerge about one week after pupation by chewing a hole through the aphid exoskeleton. Adult Aphelinus eat nectar and honeydew, but females also feed on aphids to get proteins and fatty acids for egg production and survival. Females emerge from their hosts with 10-15 mature eggs (Hopper and Diers, 2014). However, they continue to produce eggs throughout their lives and can parasitize an average 525 aphids per day, depending on age and species, and thus can parasitize 100 aphids on average during their lifetimes (unpublished data).

The literature on the hosts of Aphelinus species suffers from confounding of cryptic parasitoid species (Heraty et al., 2007), which can increase estimates of host ranges when the parasitoid species have narrow and different host ranges. Host ranges may also be underestimated because of under-reporting of host aphids that are not pests (De Nardo and Hopper, 2004). Nonetheless, citations on host species in the Universal Chalcidoid Database (Noyes, 2015) suggest that host ranges of species within the genus Aphelinus vary from broad (e.g. 40 host species for Aphelinus asychis ) to narrow (e.g. 2 host species for A. hordei). Here we report results on host specificity of 10 populations of seven species from two species complexes in the genus Aphelinus (Hymenoptera: Aphelinidae) originally collected from aphids that attack grain crops (Table 1). Host specificity did not depend on host plant species or the phylogenetic relatedness of the aphids or the parasitoids. While some species had very broad host ranges and others had intermediate host ranges, Aphelinus hordei had a very narrow host range, being restricted primarily to species in the genus Diuraphis, and especially D. noxia. We also report the results of experiments on the mechanisms of this host specificity.

\section{Materials and methods}

\subsection{Parasitoid biology, collection, and rearing}

Parasitoids were collected from 10 populations of seven Aphelinus species attacking Diuraphis noxia, Rhopalosiphum padi, or Rhopalosiphum maidis (Hemiptera: Aphididae) on wheat, barley, or maize in China, France, Israel, Republic of Georgia, and the United States 
during 1999-2011 (Table 1). All these parasitoids are in the asychis or varipes species complexes of Aphelinus, and these complexes include several cryptic species that are reproductively incompatible and phylogenetically distinct (Heraty et al., 2007; Kazmer et al., 1996).

Parasitoids were shipped or hand-carried as mummified aphids to the containment facility at the USDA-ARS, Beneficial Insect Introductions Research Unit, Newark, Delaware, and maintained under the permits indicated in Table 1. Material was screened for hyperparasitoids and insect pathogens and then cultures were established using the founding numbers indicated in Table 1. To maintain genetic variation under laboratory rearing, each culture was split into 4-6 replicate subcultures after one generation, and each subculture was maintained with an adult population size >200 (Hopper et al., 1993; Roush and Hopper, 1995). Sex ratios of emerging adults were about 1:1 males:females. Parasitoids were reared in plant growth chambers on the host and host plant species on which they were collected at $20-25^{\circ} \mathrm{C}, 50-70 \%$ relative humidity, and 16:8 h (L:D) photoperiod. Vouchers for these populations are maintained at $-20^{\circ} \mathrm{C}$ in $100 \%$ molecular grade ethanol at the Beneficial Insect Introduction Research Unit, Newark, Delaware; voucher accession numbers are given in Table 1.

\subsection{Aphid and host plants}

In several experiments, we measured parasitism and behavior of the parasitoids when exposed to 16 aphid species in six genera and two tribes on six host plant species in four families (Table 2). These aphids and host plants were chosen to provide contrasts of aphid species in the same versus different genera and tribes on the same versus different host plant species. The goal was to explore the phylogenetic and host plant limits on parasitism, as has been recommended for host specificity testing of entomophagous insects (Kuhlmann et al., 2005).

Aphids for parasitoid rearing and host specificity experiments were from laboratory cultures at Newark started from field collections in the USA during 1996-2010. Aphids were reared on plants in plant growth chambers at $20^{\circ} \mathrm{C}, 50-70 \%$ relative humidity, and $16: 8 \mathrm{~h}(\mathrm{~L}: \mathrm{D})$ photoperiod. Vouchers for these populations are maintained as described above for parasitoids.

\subsection{Measurement of parasitism}

We carried out several experiments to measure differences in parasitism among aphid and plant species for each parasitoid species and population. In the first set of experiments, we measured parasitism of seven aphid species (D. noxia, M. persicae, R. maidis, R. padi, S. 
graminum, A. glycines, A. gossypii) on four host plant species by the 10 populations of Aphelinus to test their specificity among aphid species across much of the phylogeny of aphids and on several host plant species (Table 2). When these experiments were conducted, the parasitoids had been in culture 12-52 generations.

Because the first set of experiments showed that $A$. hordei alone had a narrow host range than included $D$. noxia, we measured parasitism by $A$. hordei in an experiment involving three species of Diuraphis (D. noxia, D. tritici, D. mexicana), as well as well as 11 other aphid species (M. persicae, A. pisum, A. craccivora, A. helianthi, A. monardae, A. nerii, A. oestlundi, A. rumicis, $R$. maidis, $R$. padi, S. graminum) that included seven aphid and six plant species not used in the first set of experiments. When this experiment was conducted, A. hordei had been in culture 15-25 generations.

For these experiments, we used 1-5 day old females that had been with males and aphids since emergence and thus had the opportunity to mate, host-feed, and oviposit. We isolated females from males and aphids for $24 \mathrm{hr}$ before using them in experiments to insure that the females had a full egg load. In each experimental unit, we put a single female parasitoid in a cage (10 cm diameter by $22 \mathrm{~cm}$ tall) enclosing the foliage of a potted plant of the appropriate species with 100 aphids of mixed instars of a single species. Female parasitoids were removed after 24 hours and were used only once.

Because these parasitoids can parasitize a maximum of about 30 aphids in 24 hours, this abundance of aphids and period of exposure allowed parasitoids to use their full egg load. Furthermore, the density of aphids, amount of plant material, and cage size meant that parasitoids were not limited by search rate. We waited until the larval parasitoids killed and mummified their hosts before scoring parasitism. Therefore, we measured a combination of acceptance of hosts for oviposition and suitability of hosts for parasitoid development. This type of experiment is often called a no-choice experiment. However, female parasitoids had the choice to oviposit or not when they sequentially encountered individuals of a particular host species. This is frequently the choice aphid parasitoids have in the field because aphids are distributed in colonies often of a single aphid species. The idea was to measure parasitism in an environment that appears to harbor only one aphid species on only one plant species and where female parasitoids re-encounter this combination repeatedly starting with a full egg load. Ten days after exposure of aphids to parasitoids, we collected any mummified aphids and held them 
152 153

for adult parasitoid emergence. After the adults emerged, we recorded the number mummified aphids and the number and sex of adult parasitoids.

\subsection{Mechanisms of host specificity in Aphelinus hordei}

To determine the mechanisms affecting parasitism of aphid species by A. hordei, we directly observed behavior of female parasitoids exposed to aphids. We observed female parasitoids with each of nine aphid species (D. noxia, D. mexicana, D. tritici, M. persicae, $R$. maidis, S. graminum, A. helianthi, A. monardae, A. rumicis) that included species for which $A$. hordei did and did not produce parasitized aphids in the experiments described above. In each experimental unit, we exposed a day-old female parasitoid to ten second/third instar aphids, the preferred stages for parasitism, on an excised leaf of the appropriate plant species in small arenas (10 $\mathrm{mm}$ diameter by $4 \mathrm{~mm}$ height). The arenas were formed using two microscope slides with vinyl foam weather-stripping glued to them; on one slide, the weather-stripping had a $10 \mathrm{~mm}$ diameter hole bored in it, exposing the slide surface through which observations were made. A leaf freshly cut from a plant was clamped between the slides (weather-stripping against the leaf) and the leaf petiole placed in $1 \%$ agar in a small vial to maintain turgor. We placed aphids in the arenas about 30 minutes before beginning observations to allow them to settle and begin feeding on the leaves. We also exposed each parasitoid female to three D. noxia in an arena prior to each observation bout and counted the number fed upon. We used a randomized complete-block design with each block of nine aphid species done on a single day. When this experiment was conducted, the parasitoids had been in culture 27-78 generations.

We observed each female parasitoid and the aphids with which she was enclosed continuously for 25 minutes under a binocular stereoscope at 10-30X magnification. We recorded behavior of the parasitoids and aphids with a video camera attached to the microscope and connected to a digital videotape recorder (for date/time stamping) and a DVD burner (for archiving). Identities of aphids and sequences of behaviors were also noted by hand on maps of the arenas, and these locations and sequences were verified by reviewing the DVD recordings.

On encountering a potential host, A. hordei females stop at about half their body length away from the aphid. Without touching the aphid, females sway from side to side several times with antennae extended (which we call an approach). They then turn $180^{\circ}$ to face away from the aphid, extend their ovipositor, and insert it into the aphid (which we call a sting). Females sometimes failed to contact the aphid with their ovipositor (which we call a miss) and made 
183 184

185

186

187

188

189

190

191

192

193

194

195

196

197

198

199

200

201

202

203

204

205

206

207

208

209

210

211

212

several attempts at approaching and stinging the aphid. Besides ovipositing in an aphid, Aphelinus females may also paralyze them, make a wound with their ovipositor, and drink hemolymph from the wound (host-feeding). The aphid individuals paralyzed for feeding die, even if female parasitoids do not actually feed on them, and females do not oviposit in aphids paralyzed for feeding. When female parasitoids were exposed to aphid species that they did not approach or sting, they began to run and/or flit after a short period, suggesting that they would have left the aphid patch if they had not been constrained by the arena.

We recorded whether an aphid was approached, and if approached, the outcome of each encounter (stung, missed, host-fed). For the longest sting that did not lead to host feeding, we measured the duration of the encounter from approach until the parasitoid left the aphid (handling time), and for the longest sting that lead to host feeding, we measured the duration of the encounter from approach until the parasitoid left the aphid (host-feeding time). For aphids that were approached, we recorded the number of each type of defense behavior (kicking, bucking, rotating around while retaining mouth parts in the leaf, walking away, and cornicular secretion). We also measured patch-leaving time, which we defined as the time to flitting or running. From these data, we tabulated the number of aphids approached, the numbers of aphids stung, and the numbers of aphids fed upon. We calculated aphid defense as the number of aphids that defended themselves times the frequency of each defense behavior. We removed female parasitoids after the observation period, dissected their ovaries in Ringer's solution mixed with neutral red stain, and counted the number of mature eggs under 40-100X magnification (neutral red does not pass through the chorion of mature eggs and thus they remain unstained).

If a female parasitoid stung one or more aphids, we either dissected all the aphids from a given observation period to determine whether eggs were laid, or we transferred all the aphids from a given observation period to the appropriate host plant species and reared them to determine whether parasitoid progeny survived to aphid mummification and whether exposure to parasitoids otherwise affected aphid survival. We dissected aphids from half the replicates and reared aphids from the other half of the replicates, yielding five replicates of dissected aphids and five replicates of reared aphids per aphid species that female parasitoids stung. Aphids were dissected in batches of five on glass microscope slides, each batch placed in a small drop of Ringer's solution and covered with a separate cover slip. We counted parasitoid eggs from the 
213 dissected aphids at 40-100X magnification. For replicates in which no aphids were stung, we

214 neither dissected nor reared the aphids after observation.

\subsection{Data analysis}

In the 24-hour parasitism experiments, we tested the effects of aphid species on number of parasitized (mummified) aphids, the proportion of adult wasps that emerged from parasitized aphids, and the proportion of females among these adults. The experimental unit in these analyses was a mated, female parasitoid exposed to aphids of a single species on the appropriate host plant. Replicates in which females were not recovered or died before the end of the exposure period were not used in analyses. In the first set of experiments, missing or dead females constituted $<8 \%$ (72/910) of those exposed with $0-4$ missing for each combination of aphid species and parasitoid population. After these were removed, we had information for 6-29 females from each of the nine parasitoid populations on each of the seven aphid species for a total of 838 females. In the 24-hour experiment with A. hordei, missing or dead females constituted $<8 \%(15 / 200)$ of those exposed with 0-2 missing for each aphid species. After these were removed, we had information for 9-28 females of $A$. hordei on 14 aphid species for a total of 185 females.

In the direct observation experiment, we tested the effects of aphid species on the number of aphids that $A$. hordei females approached and stung, the number on which they host fed or in which they oviposited, and the number that were mummified. We tested the effects of aphid species on leaving time and the survival of A. hordei progeny. Lastly, we tested the differences in the amount of defense behaviors among aphid species and the relationship between oviposition and aphid defense. The experimental unit in these analyses was an unmated, female parasitoid exposed to aphids of a single species on a leaf of the appropriate host plant. We observed 10 females of $A$. hordei for each of nine aphid species.

Because the dependent variables often had non-normal distributions with variances proportional to means, we used generalized linear models with appropriate distributions (e.g. normal, binomial, negative binomial) for the dependent variable to test for effects of model factors. We chose the distribution that gave highest model probability calculated from the residual deviance divided by residual degrees of freedom compared to the chi-square distribution (Littell et al., 1996). To test the effect of aphid species on leaving time, we used the Cox 
243

proportional hazards model for right-censored data. Leave time data were right censored because parasitoids did not leave patches of aphid species that they parasitized.

Because counting eggs in aphids was destructive, we could not directly compare the number of aphids in which $A$. hordei oviposited with the number that mummified and produced adult wasps. Instead, we used Spearman's rank correlation coefficient $(\rho)$ to test the relationship between the mean number of wasp progeny and the mean number of aphids in which $A$. hordei oviposited and the relationship between the amount of aphid behavior defenses and the numbers of aphids stung, oviposited in, and host-fed upon.

For these analyses, we used cor.test, glm, glm.nb, and coxph in R version 3.2.3 (R_Core_Team, 2014). Means are given with 95\% asymptotic confidence intervals in brackets. Data are archived on the Ag Data Commons website (data.nal.usda.gov; DOI 10.15482/USDA.ADC/1337670)

\section{Results}

\subsection{Patterns of parasitism among Aphelinus species}

These Aphelinus species from grain aphids differed greatly in host range (Fig. 1). Four species (A. albipodus, A. asychis, A. atriplicis, and A. certus) parasitized all or all but one of the aphid species on all or nearly all the plant species tested. Two species (A. kurdjumovi and A. varipes) parasitized several, but not all, of the aphid species on several plant species. Aphelinus hordei, which parasitized one aphid species on one plant species, was the only species with a narrow host range. Within these categories, species showed different host specificities (Table 3). Parasitism by both populations of A. asychis did not differ among aphid species, nor was there an interaction between collection host and aphid species in their effects on parasitism. However, $A$. asychis originally collected from $R$. padi produced more parasitized aphids than those collected from D. noxia. Parasitism differed marginally among aphid species for A. albipodus, mostly because of low parasitism of $M$. persicae. Parasitism differed among aphid species for $A$. atriplicis, and collection country interacted with aphid species in their effects on parasitism. Aphelinus atriplicis from the Republic of Georgia parasitized few M. persicae and moderate numbers of $A$. gossypii, whereas A. atriplicis from the USA parasitized few A. gossypii and many M. persicae. Aphelinus certus readily parasitized all aphid species on all plant species, except for 
272 D. noxia, which it rarely parasitized. Aphelinus hordei was the only parasitoid that specialized on 273 D. noxia.

274 Rates of adult emergences from mummified aphids were high (means 0.7-1.0 adults per 275 mummified aphid) for all aphids but M. persicae, for which parasitoid species that showed low

276 parasitism tended to show low emergence (Fig. 2). This caused significant effects of aphid 277 species on rates of adult emergences for six of the seven Aphelinus species studied (Table 4). For 278 A. hordei, emergence rates were high, even for aphid species it rarely parasitized, except $M$. 279 persicae, from which parasitoid adults rarely emerged.

Adult sex ratios were highly variable within aphid species (Fig. 3), and for five out of the seven Aphelinus species, sex ratio did not differ among aphid species they parasitized (Table 5). Aphelinus kurdjumovi and A. varipes had male-biased sex ratios when they parasitized Aphis species, suggesting that these aphids may be poor quality hosts for these parasitoid species. For the other Aphelinus species, sex ratio did not significantly differ from 1:1, although the sex ratios of $A$. hordei on D. noxia and S. graminum tended to be female-biased.

\subsection{Host specificity of Aphelinus hordei}

In the experiment on the host specificity of $A$. hordei, parasitism varied strongly among aphid species (model deviance $=98.0, \mathrm{df}=13$; residual deviance $=111.7, \mathrm{df}=171 ; P<$ 0.00001). Aphelinus hordei parasitized primarily species in the genus Diuraphis, particularly $D$. noxia, and little or no parasitism outside this genus (Fig. 4). Rates of adult emergences from mummified aphids where high for D. noxia (mean $=0.89$ [0.77-1.00]), D. mexicana (0.84 [0.691.00]), and S. graminum (0.95 [0.75-1.00]), but lower for D. tritici (0.66 [0.46-0.85]) and A. monardae (0.56 [0.26-0.85]). However, the low number of replicates with parasitized aphids for species other than $D$. noxia meant that adult emergence rates were not quite significantly different among aphid species (model deviance $=0.6, \mathrm{df}=4$; residual deviance $=3.0, \mathrm{df}=43 ; P$ $=0.07$ ). Adult sex ratios did not differ from 1:1 and were not affected by aphid species (model deviance $=0.4, \mathrm{df}=3$; residual deviance $=5.7 \mathrm{df}=39 ; P=0.48)$.

\subsection{Mechanisms of host specificity in Aphelinus hordei}

Most of the host specificity of A. hordei can be explained by differences in the behavior of females when they encountered different aphid species (Fig. 5; Table 6). When exposed to species in the genus Diuraphis, A. hordei females approached 5-8 aphids on average during the 
25-minute observation periods. Rhopalosiphum maidis and S. graminum were the only nonDiuraphis species approached with even moderate frequency.

Within the genus Diuraphis, A. hordei females stung most of the aphids they approached, although there was a tendency to sting $D$. noxia more per approach than $D$. mexicana and $D$. tritici (90\% and $84 \%$ of approaches, respectively, led to stings versus $96 \%$ for D. noxia). Outside the genus Diuraphis, A. hordei females stung both R. maidis and S. graminum $45 \%$ of the time they were approached, but the other non-Diuraphis species were never stung. Although A. hordei females approached and stung D. mexicana and D. tritici as often or more often than D. noxia, they oviposited more often in D. noxia (3 [2-6] aphids with eggs) than in the other Diuraphis species (2 [1-4] aphids with eggs). This meant that the proportion of aphids in which parasitoids oviposited per aphid stung was higher for D. noxia (0.64) than for D. mexicana (0.42) or D. tritici (0.28). Aphelinus hordei females rarely oviposited in S. graminum, and never oviposited in other non-Diuraphis species. Handling time of aphids that were not fed upon varied among aphid species (Table 6), from a mean of 69 [48-100] seconds for D. noxia to a mean of 24 [16-36] seconds for $R$. maidis (Fig. 6). This variation may have arisen from longer times for stings involving oviposition than for stinging without oviposition, together with fewer ovipositions in species other than D. noxia and particularly in non-Diuraphis species. Mean duration of stings of females correlated with the number of eggs they laid in aphids (Spearman's $\rho=0.78, P<$ 0.00001), suggesting that stings with oviposition took longer than stings without oviposition. The distribution of sting durations was bimodal, and the mean sting duration for females of $A$. hordei that laid one or more eggs in aphids was 3.5-fold longer than that for females that laid no eggs (14 [11-16] seconds versus 48 [44-52] seconds, respectively), which also supports the idea that stings for oviposition took longer.

Survival of $A$. hordei progeny in D. noxia was higher (75\%) than in D. mexicana (36\%) or D. tritici (22\%), which may explain part of the differences in realized parasitism among these aphid species in the experiments above. The mean number of aphids that were mummified was strongly correlated with the mean number of aphids in which females oviposited (Spearman's $\rho$ $=0.98, P<0.00001)$.

The numbers of aphids that were host fed varied with aphid species, with female $A$. hordei feeding only on Diuraphis species (Table 6). Female A. hordei consumed 0.7 [0.3-1.5] D. noxia, 0.5 [0.2-1.2] D. tritici, and 0.4 [0.2-1.1] D. mexicana, during the 25-minute observation 
333

period, but these differences were not significant (model deviance $=0.9$, $\mathrm{df}=2$; residual deviance $=24.8, \mathrm{df}=27 ; P=0.65)$. Handling times for aphids that were fed upon were 9-17 fold longer than for aphids that were not fed upon, being 687 [494-956] seconds for $D$. mexicana, 631 [512-778] seconds for D. noxia, and 537 [435-662] seconds for D.tritici, but the differences were not significant (Table 6). The main difference was in the duration of stings that were 6-8 times longer than for aphids that were not host-fed and the duration of host-feeding that were as long or longer than the duration of stings.

Among aphids approached by A. hordei, defense behavior varied among aphid species (Table 6), with D. noxia defending itself least and S. graminum most (Fig. 7). Neither the number of aphids in which females oviposited nor the number of aphids on which they host-fed correlated with the amount of defense behavior by aphids (Spearman's $\rho=0.11, P=0.15 ; \rho=$ $0.09, P=0.27$, respectively), and the number of aphids stung correlated positively, rather than negatively correlated, with the amount of defense behavior (Spearman's $\rho=0.59, P<0.00001$ ).

The time to patch leaving by A. hordei females were much longer for Diuraphis species than for other aphid species (Fig. 8; Cox proportional-hazards likelihood ratio $=39.5$, $\mathrm{df}=8, P<$ $0.00001)$.

At the start of the observation periods, female A. hordei with four ovarioles carried 13 [12-14] eggs and females with six ovarioles carried 17 [14-20] eggs (range 2-33). Female $A$. hordei oviposited $8 \%$ of their eggs on average during the 25 -minute observation periods. Although two females carried only two eggs and one carried three eggs, the rest of the females carried at least six eggs, and a maximum of four eggs were laid in aphids, so these females did not appear to be egg-limited. Furthermore, there was no correlation between the numbers of aphids in which female $A$. hordei laid eggs and their egg loads (Spearman's $\rho=-0.09, P=0.70$ ).

\section{Discussion}

Among the seven Aphelinus species we tested, which included all species found on grain crops during exploration for parasitoids of D. noxia in Eurasia (Heraty et al., 2007; Hopper et al., 1998), only A. hordei specialized on Diuraphis species, and in particular, D. noxia. The specialization on Diuraphis species resulted from oviposition restricted almost exclusively to aphids in this genus. Female $A$. horde $i$ very rarely approached aphids on host plants other than barley, and even with aphids on barley, walked over non-host aphid species, completely ignoring them. Furthermore, A. hordei rarely stung non-Diuraphis species but did sting exuviae of 
Diuraphis species. Female A. hordei rarely touched host aphids or exuviae with their antennae but did orient head-first towards them at a distance before stinging them. Within Diuraphis, female A. hordei oviposited more and their progeny survived better in D. noxia than in other species. Although A. hordei females approached and stung as many or more D. mexicana and $D$. tritici as $D$. noxia, the proportion of aphids in which parasitoids oviposited per aphid stung for $D$. noxia was $51 \%$ higher than for D. mexicana and $127 \%$ higher than for D. tritici, suggesting that parasitoid evaluation of host quality may be mediated in part by sensilla on their ovipositors. Together, these results suggest two steps may be involved in A. hordei parasitism of hosts: recognition of a potential host, perhaps by detection of cuticular hydrocarbons in the aphid cuticle with sensilla on the antennae (or elsewhere), and then acceptance of the aphid for oviposition mediated by sensilla on the ovipositor after potential hosts are stung. Females of $A$. hordei also specialized on Diuraphis species for host feeding, and they host fed more on $D$. noxia than on the other Diuraphis species, which suggests that the same cues may be used for recognition and acceptance of aphid species for both feeding and oviposition.

The short times to patch-leaving behavior by A. hordei on non-Diuraphis species also suggest that it would not parasitize these species in the field. The occasional parasitism of nonDiuraphis species in both the behavioral experiments and the 24-hour experiments may have resulted from parasitoids revisiting patches of aphids that they would not have revisited if they had been allowed to disperse.

Such taxonomic specialization might suggest that host specificity in Aphelinus species is related to phylogenetic relatedness of the aphid species or to the chemistry of their host plants. However, A. kurdjumovi and A. varipes both parasitized $R$. padi and S. graminum equally well, but rarely parasitized $R$. maidis, a congener of $R$. padi. The four other parasitoid species attacked most or all of the aphid species to which they were exposed, so phylogenetic relatedness of the aphids could not have an effect on them. Host specificity was not determined by host plant species. For example, A. hordei parasitized Diuraphis species on barley but ignored the other species on this host plant, while A. kurdjumovi parasitized only two of the four species on barley, but $A$. varipes parasitized aphids on barley, cotton and soybean. Lastly, the four generalist parasitoids parasitized aphids on most or all the host plant species, some of which had very different chemistries. 
Phylogenetic relatedness of parasitoids also failed to explain patterns in host specificity. Aphelinus hordei and A. kurdjumovi are closely related (Heraty et al., 2007), but their host specificities are non-overlapping. Aphelinus atriplicis and A. varipes are also closely related and show low levels of reproductive compatibility, with $8 \%$ of crosses between $A$. atriplicis females and $A$. varipes males yielding female progeny (Heraty et al., 2007). Although they both parasitized all the aphid species tested, A. atriplicis did equally well on most species, while $A$. varipes had high fitness on only two species.

The shorter handling times of $A$. hordei for species other than D. noxia may reflect female parasitoid rejection of poor host quality during stings, which would lead to less frequent oviposition and thus shorter handling times, which is supported by significantly shorter handling times for parasitoids that did not lay eggs in aphids than for those that did. Like other Aphelinus species, A. hordei has relatively large, anhydropic eggs that appear to take a long time to pass through their long, thin ovipositors into host aphids. In support of this idea, the handling times for A. hordei are much longer than those reported for the other major group of aphid parasitoids, the aphidiine braconids (Wu et al., 2011) that carry much smaller eggs and have much shorter ovipositors with a large egg canal (Le Ralec et al., 1986). These long handling times have implications for the impacts of intraguild predation on parasitoid foraging behavior (Martinou et al., 2010), and probably mean that A. hordei is unlikely to attack ant-defended aphids (Wyckhuys et al., 2009).

Our results on the lack of correlation between defense behavior by aphids and oviposition or host feeding by $A$. hordei females, together withe the positive correlation between defense behavior and stinging of aphids by $A$. hordei females, suggest that more parasitoid attacks elicited more, but ultimately ineffective, defensive behaviors by the aphids.

Comparing our results with Aphelinus host specificity from the literature is difficult because there are no previous publications that evaluate Aphelinus specificity experimentally. All the published evidence on Aphelinus specificity is from field collections of parasitized aphids. Host specificity obtained by rearing parasitoids from field-collected hosts suffers from two major problems. First, publications about host species from field collections almost always state that the parasitoid species was reared from a host species but do not estimate parasitism levels. In our experiments, we found parasitism of some aphid species at very low levels for some parasitoid species, and field records might include these aphids in the host range of the parasitoids even 
though they are rarely attacked. Second, closely related Aphelinus species can be very difficult to distinguish so that host records from the literature may confound cryptic species of parasitoids. In particular, Yasnosh (1978) reported that D. noxia was a host of A. varipes, but later reported that this was a misidentification of what was actually A. hordei (Yasnosh, 2002). Ferriere (1965) synonymized $A$. horde $i$ with $A$. varipes and the synonymy was supported by Graham (1976), but this synonymy is incorrect because the two species are reproductively incompatible and phylogenetically distinct (Heraty et al., 2007), despite being difficult to distinguish morphologically (Prinsloo et al., 2002). The results reported here show that A. varipes does not parasitize D. noxia, whereas A. hordei is a specialist on Diuraphis species, and especially $D$. noxia.

Narrow host ranges are rare among aphidiine braconids, but some species in this group do show relatively narrow host ranges (Desneux et al., 2009). Nonetheless, the limited experimental results on aphidiine braconids compared with our results on Aphelinus species suggest that the latter have a greater diversity of host specificities, including extremes within the same species complex, like $A$. hordei with a very narrow host range versus $A$. atriplicis with a very broad host range.

Aphidiine braconids antennate and bend their abdomens towards aphid exuviae (essentially empty cuticles) and chemicals extracted from these exuviae, which can include hydrocarbons, wax esters, alcohols, and aldehydes (Muratori et al., 2006). Aphelinus species will also sting aphid exuviae, suggesting that exuviae contain chemicals involved in Aphelinus host recognition. Although $A$. hordei females stung aphid species other than D. noxia, including species in genera other than Diuraphis, A. hordei females almost never laid eggs in species in other genera. Furthermore, the ratio of ovipositions to stings was higher for D. noxia than for other Diuraphis species. These results suggest that $A$. hordei females use cues on aphid cuticles to decide whether to sting and cues inside aphids to decide whether to oviposit. We are now studying the parasitoid genes that could be involved in these decisions.

Our results show that $A$. hordei is specialist on Diuraphis species, and particularly $D$. noxia. This specialization results from almost exclusive acceptance of Diuraphis species for oviposition and from higher oviposition and survival of progeny in D. noxia than in the other Diuraphis species. The narrow specificity of A. hordei makes it an excellent candidate for introduction into the USA to control D. noxia. 


\section{Acknowledgements}

457 This research was supported by the United States Department of Agriculture, Agricultural

458 Research Service, by a United States Department of Agriculture National Research Initiative 459 Grant 2002-35302-12710 to KRH, JBW, and JMH, and by a United States National Science 460 Foundation Grant DEB 1257601 to JBW and KRH. 


\section{References}

Basky, Z., Hopper, K.R., 2000. Impact of plant density and natural enemy exclosure on abundance of Diuraphis noxia (Kurdjumov) and Rhopalosiphum padi (L.) (Hom., Aphididae) in Hungary. Journal of Applied Entomology 124, 99-103.

Brewer, M.J., Noma, T., Elliott, N.C., 2005. Hymenopteran parasitoids and dipteran predators of the invasive aphid Diuraphis noxia after enemy introductions: Temporal variation and implication for future aphid invasions. Biological Control 33, 315-323.

Brooks, L., Hein, G., Johnson, G., Legg, D., Massey, B., Morrison, P., Weiss, M., Peairs, F., 1994. Economic impact of the Russian wheat aphid in the western United States: 19911992. In: Peairs, F.B., Kroening, M.K., Simmons, C.L., Eds.), Proceedings of the 6th Russian Wheat Aphid Workshop. Great Plains Agricultural Council Publication, Fort Collins, Colorado, pp. 250--268.

Chen, K., Hopper, K.R., 1997. Diuraphis noxia (Homoptera: Aphididae) population dynamics and impact of natural enemies in the Montpellier region of southern France. Environmental Entomology 26, 866-875.

Christiansen-Weniger, P., 1994. Morphological observations on the preimaginal stages of Aphelinus varipes (Hym., Aphelinidae) and the effects of this parasitoid on the aphid Rhopalosiphum padi (Hom., Aphididae). Entomophaga 39, 267-274.

Dahleen, L.S., Bregitzer, P., Mornhinweg, D., Klos, K.E., 2015. Genetic diversity for Russian wheat aphid resistance as determined by genome-wide association mapping and inheritance in progeny. Crop Science 55, 1925-1933.

De Farias, A.M.I., 1995. Parasitoids and hyperparasitoids (Hymenoptera) associated with Diuraphis noxia (Kurdumov, 1913) (Homoptera: Aphididae) in the region of Montpellier. Ecole Nationale Superieure Agronomique de Montpellier, Montpellier, pp. 120.

De Nardo, E.A.B., Hopper, K.R., 2004. Using the literature to evaluate parasitoid host ranges: a case study of Macrocentrus grandii (Hymenoptera : Braconidae) introduced into North America to control Ostrinia nubilalis (Lepidoptera : Crambidae). Biological Control 31, 280-295.

Desneux, N., Barta, R.J., Hoelmer, K.A., Hopper, K.R., Heimpel, G.E., 2009. Multifaceted determinants of host specificity in an aphid parasitoid. Oecologia 160, 387-398.

Fauvergue, X., Hopper, K.R., 2009. French wasps in the New World: experimental biological 
control introductions reveal a demographic Allee effect. Population Ecology 51, 385-397.

Fauvergue, X., Hopper, K.R., Antolin, M., 1995. Mate-finding via a trail sex pheromone by a parasitoid wasp. Proceedings of the National Academy of Sciences 92, 900-904.

Fazel-Najafabadi, M., Peng, J.H., Peairs, F.B., Simkova, H., Kilian, A., Lapitan, N.L.V., 2015. Genetic mapping of resistance to Diuraphis noxia (Kurdjumov) biotype 2 in wheat (Triticum aestivum L.) accession CI2401. Euphytica 203, 607-614.

Feng, M.G., Johnson, J.B., Halbert, S.E., 1992. Parasitoids (Hymenoptera, Aphidiidae and Aphelinidae) and their effect on aphid (Homoptera, Aphididae) populations in irrigated grain in southwestern Idaho. Environmental Entomology 21, 1433-1440.

Fernandez, V.N., Perez, E.N., Santero, E.D., Nafria, J.M.N., 1992. Situacion en el norte de espana del pulgon ruso del trigo, Diuraphis noxia (Mordvilko) (Hom., Aphididae). Georgica 1, 9-24.

Ferrière, C., 1965. Hymenoptera Aphelinidae d'Europe et du Bassin Mediterraneen. Masson and Associates, Paris.

Graham, M.W.R.D.V., 1976. British species of Aphelinus with notes and descriptions of other European Aphelinidae (Hymenoptera). Systematic Entomology 1, 123-146.

Grossheim, N.A., 1914. The barley aphid, Brachycolus noxius Mordwilko. Mem. Nat. Hist. Mus. Zemstwo Province Tavria 3, 35-78.

Haley, S.D., Peairs, F.B., Walker, C.B., Rudolph, J.B., Randolph, T.L., 2004. Occurrence of a new Russian wheat aphid biotype in Colorado. Crop Science 44, 1589-1592.

Heraty, J.H., Woolley, J.B., Hopper, K.R., Hawks, D.L., Kim, J.-W., Buffington, M., 2007. Molecular phylogenetics and reproductive incompatibility in a complex of cryptic species of aphid parasitoids. Molecular Phylogenetics and Evolution 45, 480-493.

Hopper, K.R., Aidara, S., Agret, S., Cabal, J., Coutinot, D., Dabire, R., Lesieux, C., Kirk, G., Reichert, S., Tronchetti, F., 1995. Natural enemy impact on the abundance of Diuraphis noxia (Homoptera: Aphididae) in wheat in southern France. Environmental Entomology 24, 402-408.

Hopper, K.R., Coutinot, D., Chen, K., Mercadier, G., Halbert, S.E., Kazmer, D.J., Miller, R.H., Pike, K.S., Tanigoshi, L.K., 1998. Exploration for natural enemies to control Diuraphis noxia in the United States. In: Quissenbery, S.S., Peairs, F.B., Eds.), A response model for an introduced pest-- The Russian wheat aphid. Entomological Society of America, 
Lanham, MD, pp. 166-182.

Hopper, K.R., Diers, B.W., 2014. Parasitism of soybean aphid by Aphelinus species on soybean susceptible versus resistant to the aphid. Biological Control 76, 101-106.

Hopper, K.R., Roush, R.T., Powell, W., 1993. Management of Genetics of Biological-Control Introductions. Annual Review of Entomology 38, 27-51.

Hopper, K.R., Woolley, J.B., Hoelmer, K., Wu, K., Qiao, G., Lee, S., 2012. An identification key to species in the mali complex of Aphelinus (Hymenoptera, Chalcidoidea) with descriptions of three new species. Journal of Hymenoptera Research 26, 73-96.

Kazmer, D.J., Maiden, K., Ramualde, N., Coutinot, D., Hopper, K.R., 1996. Reproductive compatibility, mating behavior, and random amplified polymorphic DNA variability in some Aphelinus asychis (Hymenoptera: Aphelinidae) derived from the Old World. Annals of the Entomological Society of America 89, 212-220.

Kuhlmann, U., Schaffner, U., Mason, P.G., 2005. Selection of non-target species for host specificity testing of entomophagous biological control agents. In: Hoddle, M., (Ed.), Second International Symposium on Biological Control of Arthropods. USDA Forest Service, Davos, Switzerland, pp. 566-583.

Lajeunesse, S.E., Johnson, G.D., 1991. New North American host records for Aphelinus sp. nr. varipes (Foerster) (Hymenoptera: Aphelinidae): The western wheat aphid, Diuraphis tritici (Gillette), and the Russian wheat aphid Diuraphis noxia (Mordvilko) (Homoptera: Aphididae). Canadian Entomologist 123, 413-415.

Le Ralec, A., Barbier, R., Nenon, J.P., Rabasse, J.M., 1986. The ovary and ovipositor of Aphidius uzbekistanicus (Hymenoptera, Aphidiidae) a parasitoid of cereal aphids anatomy and functioning. Bulletin De La Societe Zoologique De France-Evolution Et Zoologie 111, 211-220.

Littell, R.C., Milliken, G.A., Stroup, W.W., Wolfinger, R.D., 1996. Generalized linear mixed models, Chapter 10. SAS System for Mixed Models, pp. 423-460.

Martinou, A.F., Raymond, B., Milonas, P.G., Wright, D.J., 2010. Impact of intraguild predation on parasitoid foraging behaviour. Ecological Entomology 35, 183-189.

Morrison, W.P., Peairs, F.B., 1998. Response model concept and economic impact. In: Quisenberry, S.S., Peairs, F.B., Eds.), Response model for an introduced pest - the Russian wheat aphid. Thomas Say Publications in Entomology, Lanham, MD, pp. 1-11. 
Muratori, F., Le Ralec, A., Lognay, G., Hance, T., 2006. Epicuticular factors involved in host recognition for the aphid parasitoid Aphidius rhopalosiphi. Journal of Chemical Ecology 32, 579-593.

Noma, T., Brewer, M.J., Pike, K.S., Gaimari, S.D., 2005. Hymenopteran parasitoids and dipteran predators of Diuraphis noxia in the west-central Great Plains of North America: Species records and geographic range. BioControl 50, 97-111.

Noyes, J.S., 2015. Universal Chalcidoidea Database. World Wide Web electronic publication. www.nhm.ac.uk/entomology/chalcidoids/index.html.

Prinsloo, G., Chen, Y., Giles, K.L., Greenstone, M.H., 2002. Release and recovery in South Africa of the exotic aphid parasitoid Aphelinus hordei verified by the polymerase chain reaction. BioControl 47, 127-136.

Puterka, G.J., Giles, K.L., Brown, M.J., Nicholson, S.J., Hammon, R.W., Peairs, F.B., Randolph, T.L., Michaels, G.J., Bynum, E.D., Springer, T.L., Armstrong, J.S., Mornhinweg, D.W., 2015. Change in Biotypic Diversity of Russian Wheat Aphid (Hemiptera: Aphididae) Populations in the United States. Journal of Economic Entomology 108, 798-804.

R_Core_Team, 2014. R: A language and environment for statistical computing. R Foundation for Statistical Computing, Vienna, Austria.

Randolph, T.L., Peairs, F., Weiland, A., Rudolph, J.B., Puterka, G.J., 2009. Plant responses to seven Russian wheat aphid (Hemiptera: Aphididae) biotypes found in the United States. Journal of Economic Entomology 102, 1954-1959.

Rohne, O., 2002. Effect of temperature and host stage on performance of Aphelinus varipes Förster (Hym., Aphelinidae) parasitizing the cotton aphid, Aphis gossypii Glover (Hom., Aphididae). Journal of Applied Entomology 126, 572-576.

Roush, R.T., Hopper, K.R., 1995. Use of single family lines to preserve genetic variation in laboratory colonies. Annals of the Entomological Society of America 88, 713-717.

Shirley, X.A., Woolley, J.B., Hopper, K.R., 2016. Revision of the asychis species group of Aphelinus (Hymenoptera: Aphelinidae). Journal of Hymenoptera Research, In press.

Stoetzel, M.B., 1987. Information on and identification of Diuraphis noxia (Homoptera: Aphididae) and other aphid species colonizing leaves of wheat and barley in the United States. Journal of Economic Entomology 80, 696-704.

Tuatay, N., Remaudière, G., 1964. First contribution to the catalogue of Aphididae (Homoptera) 
of Turkey. Rev. Pathol. Veg. Entomol. Agron. France 43, 243-278.

Wraight, S.P., Poprawski, T.J., Meyer, W.L., Peairs, F.B., 1993. Natural enemies of Russian wheat aphid (Homoptera: Aphididae) and associated cereal aphid species in springplanted wheat and barley in Colorado. Environmental Entomology 22, 1383-1391.

Wu, G.-M., Barrette, M., Boivin, G., Brodeur, J., Giraldeau, L.-A., Hance, T., 2011. Temperature influences the handling efficiency of an aphid parasitoid through body size-mediated effects. Environmental Entomology 40, 737-742.

Wyckhuys, K.A.G., Koch, R.L., Kula, R.R., Heimpel, G.E., 2009. Potential exposure of a classical biological control agent of the soybean aphid, Aphis glycines, on non-target aphids in North America. Biological Invasions 11, 857-871.

Yasnosh, V.A., 1978. Family Aphelinidae (Aphelinids) (Section 15). In: Medvedev, G.S., (Ed.), Keys to the insects of the European part of the USSR. Volume III. Hymenoptera. Part II. Academy of Sciences of the USSR, pp. 865-916.

Yasnosh, V.A., 2002. Annotated check list of the Aphelinidae (Hymenoptera: Chalcidoidea), parasitoids of aphids (Homoptera: Aphidoidea) in Georgia. Proceedings of the Institute of Zoology, Academy of Sciences of Georgia 21, 169-172. 
603

604

605

606

607

608

609

610

611

612

613

614

615

616

617

618

619

620

621

622

623

624

625

626

627

628

629

630

631

\section{Figure captions}

Fig. 1. Parasitism of seven species of aphids exposed to species in the genus Aphelinus collected from wheat, barley, and maize. Diamonds are means and vertical lines are asymptotic 95\% confidence intervals of the means. Upper and lower sides of the boxes indicate lower and upper quartiles and the horizontal line indicates the median. Grey dots are outliers beyond the quartiles. Host plants on which aphids were exposed are indicated by the fill colors of the boxes: green $=$ barley; brown $=$ radish; yellow $=$ soybean; white $=$ cotton .

Fig. 2. Adult emergences from seven species of aphids parasitized by species in the genus Aphelinus collected from wheat, barley, and maize. Diamonds are means and vertical lines are asymptotic $95 \%$ confidence intervals of the means. Upper and lower sides of the boxes indicate lower and upper quartiles and the horizontal line indicates the median. Grey dots are outliers beyond the quartiles. Host plants on which aphids were exposed are indicated by the fill colors of the boxes: green $=$ barley; brown $=$ radish; yellow $=$ soybean; white $=$ cotton .

Fig. 3. Sex ratios of adults emerging from seven species of aphids parasitized by species in the genus Aphelinus collected from wheat, barley, and maize. Diamonds are means and vertical lines are asymptotic $95 \%$ confidence intervals of the means. Upper and lower sides of the boxes indicate lower and upper quartiles and the horizontal line indicates the median. Grey dots are outliers beyond the quartiles. Host plants on which aphids were exposed are indicated by the fill colors of the boxes: green = barley; brown = radish; yellow $=$ soybean; white $=$ cotton .

Fig. 4. Parasitism of 14 species of aphids exposed to Aphelinus hordei. Diamonds are means and vertical lines are asymptotic $95 \%$ confidence intervals of the means. Boxes indicate lower and upper quartiles and the horizontal line indicates the median. Grey dots are outliers beyond the quartiles.

Fig. 5. Behavior of Aphelinus hordei when exposed to nine species of aphids. Symbols represent means and vertical lines are asymptotic $95 \%$ confidence intervals of the means.

Fig. 6. Handling times of aphids not host-fed for Aphelinus hordei on species of aphids in which female parasitoids oviposited. Diamonds are means and vertical lines are asymptotic 95\% confidence intervals of the means. Upper and lower sides of the boxes indicate lower and upper quartiles and the horizontal line indicates the median. Grey dots are outliers beyond the quartiles. 
632 Fig. 7. Amount of defense behavior by aphid species in which female Aphelinus hordei would 633 oviposit. Diamonds are means and vertical lines are asymptotic $95 \%$ confidence intervals of the 634 means. Upper and lower sides of the boxes indicate lower and upper quartiles and the horizontal 635 line indicates the median. Grey dots are outliers beyond the quartiles.

636 Fig. 8. Leaving times Aphelinus hordei when exposed to nine species of aphids. Diamonds are 637 means and vertical lines are asymptotic 95\% confidence intervals of the means. Upper and lower 638 sides of the boxes indicate lower and upper quartiles and the horizontal line indicates the median. 639 Grey dots are outliers beyond the quartiles. 
A. hordei from 2000


\section{A. asychis from $R$. padi}

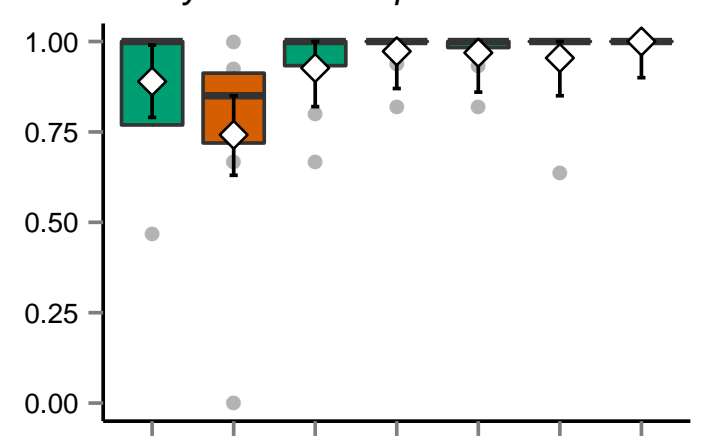

A. atriplicis from USA



A. kurdjumovi



\section{A. albipodus}



A. certus

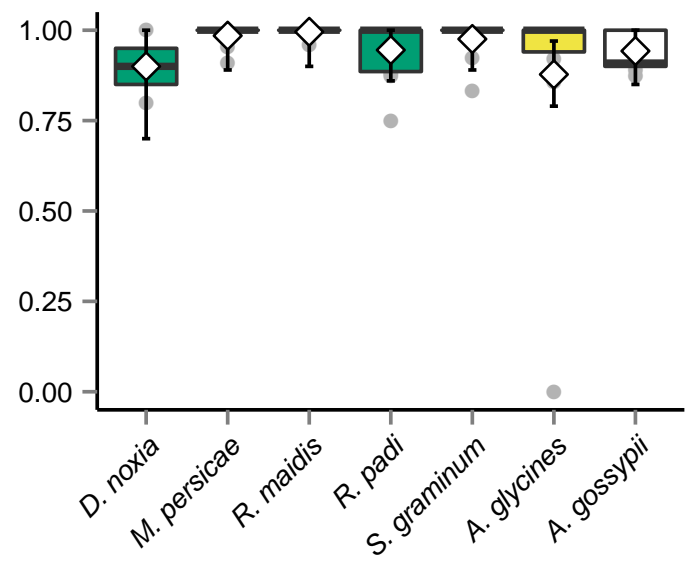

aphid species
A. varipes

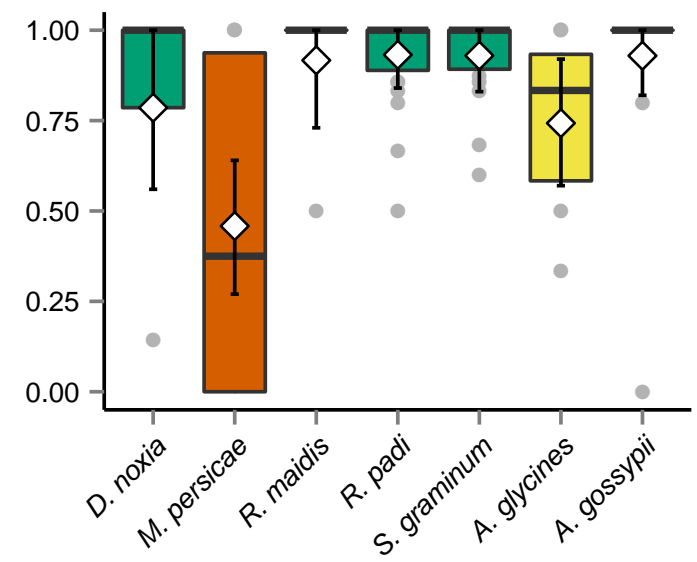


A. asychis from D. noxia

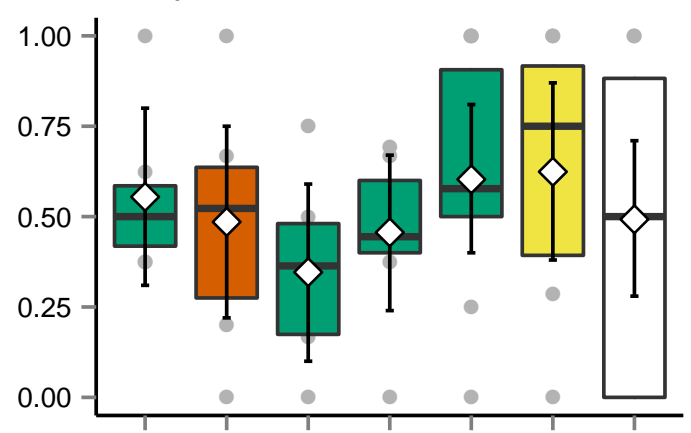

A. asychis from R. padi

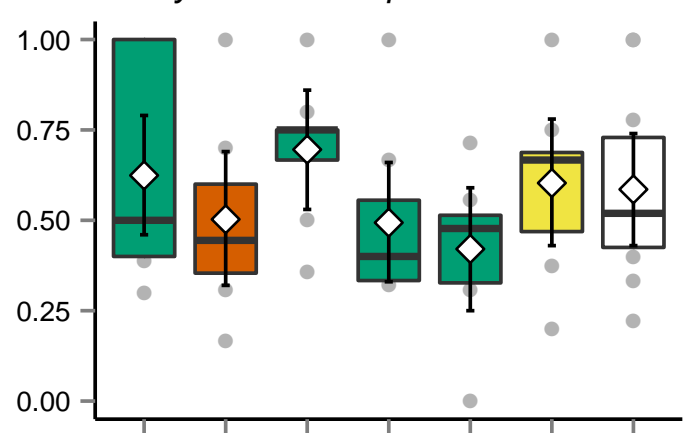

A. albipodus

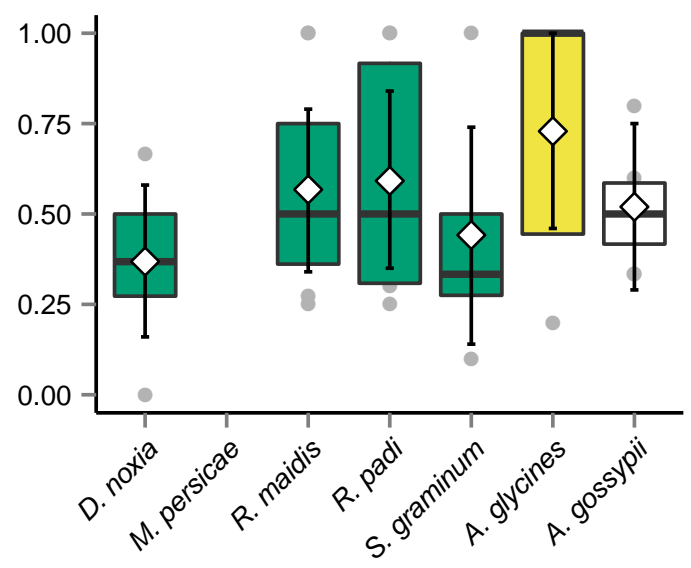

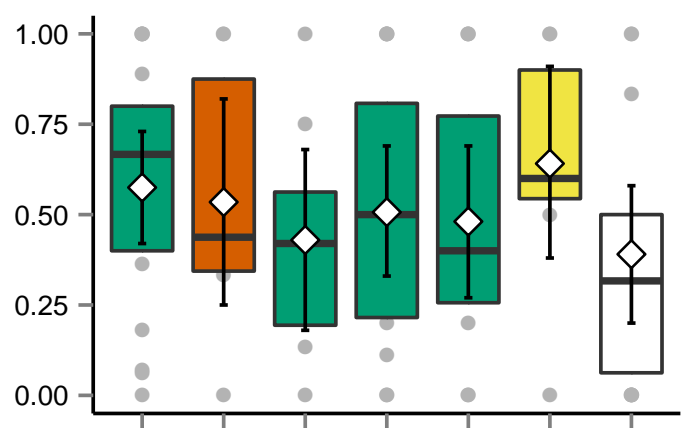

A. atriplicis from USA



A. certus



aphid species



A. kurdjumovi

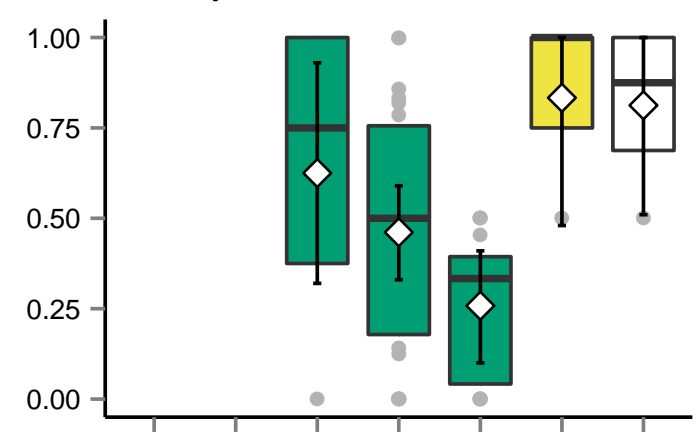

A. varipes

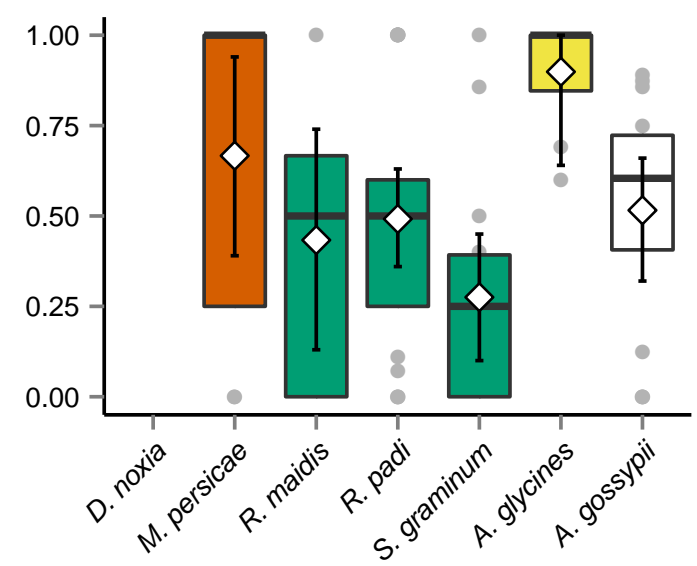







behavior






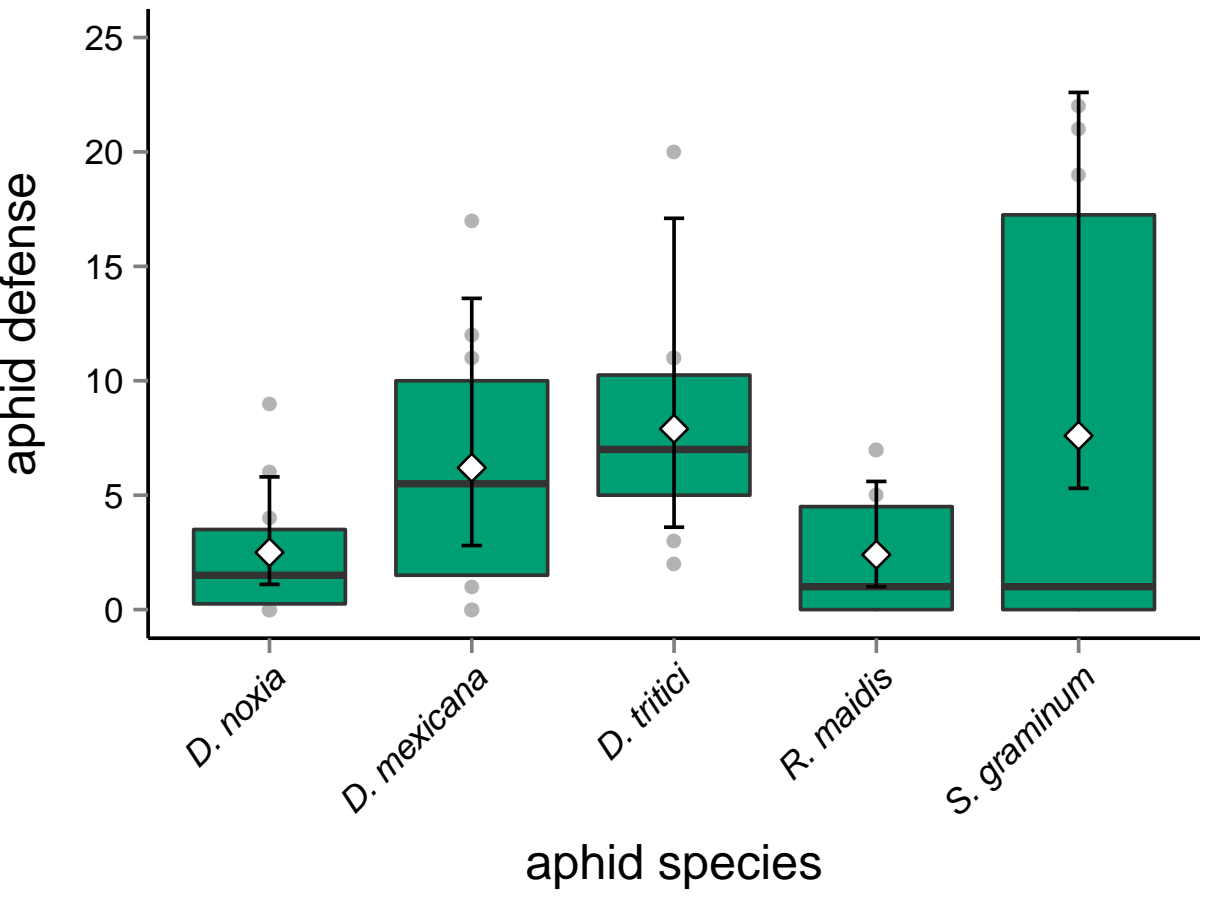







Table 1. Origins of Aphelinus species collected from grain aphids and tested for host specificity on Diuraphis noxia. All

\begin{tabular}{|c|c|c|c|c|c|c|c|c|c|}
\hline complex & species & $\begin{array}{l}\text { Aphid } \\
\text { host }\end{array}$ & Country & Region & Locations & Number & Year & Collectors & Permit and Voucher \\
\hline \multirow{5}{*}{ asychis } & asychis Walker & D. noxia & France & Herault & $\begin{array}{l}\text { Prades-le- } \\
\text { Lez }\end{array}$ & $>200$ & 2000 & $\begin{array}{l}\text { N. Ramualde, } \\
\text { D. Coutinot, } \\
\text { J. Lopez }\end{array}$ & $\begin{array}{l}\text { P526P-15-04274, } \\
\text { AFr00_Dn }\end{array}$ \\
\hline & asychis Walker & R. padi & France & Herault & $\begin{array}{l}\text { Prades-le- } \\
\text { Lez }\end{array}$ & $>200$ & 2000 & $\begin{array}{l}\text { N. Ramualde, } \\
\text { D. Coutinot, } \\
\text { J. Lopez }\end{array}$ & $\begin{array}{l}\text { P526P-13-02503, } \\
\text { AFr00_Rp }\end{array}$ \\
\hline & $\begin{array}{l}\text { albipodus Hayat \& } \\
\text { Fatima }\end{array}$ & R. padi & Israel & Judea & Gedera & 81 & 1999 & K. Hopper & $\begin{array}{l}\text { P526P-13-02503, } \\
\text { VIsr99 }\end{array}$ \\
\hline & atriplicis Kurdjumov & D. noxia & $\begin{array}{l}\text { Republic } \\
\text { of Georgia }\end{array}$ & Tbilisi & Satchergesi & 101 & 2000 & D. Coutinot & $\begin{array}{l}\text { P526P-15-04274, } \\
\text { VGg00_Dn }\end{array}$ \\
\hline & atriplicis Kurdjumov & D. noxia & USA & $\begin{array}{l}\text { Colorado, } \\
\text { Nebraska, } \\
\text { Wyoming }\end{array}$ & $\begin{array}{l}\text { Sterling, } \\
\text { Scottsbluff, } \\
\text { Cheyenne }\end{array}$ & 584 & 2006 & K. Hopper & $\begin{array}{l}\text { P526P-15-04274, } \\
\text { VUS06_Co12 }\end{array}$ \\
\hline \multirow[t]{5}{*}{ varipes - } & certus Yasnosh & $\begin{array}{l}R . \\
\text { maidis }\end{array}$ & China & Hebei & Langfang & 88 & 2005 & K. Hopper & $\begin{array}{l}\text { P526P-13-02503, } \\
\text { VCh05_Lfm }\end{array}$ \\
\hline & hordei Kurdjumov & D. noxia & France & Herault & $\begin{array}{l}\text { Prades-le- } \\
\text { Lez }\end{array}$ & 40 & 2000 & $\begin{array}{l}\text { N. Ramualde, } \\
\text { D. Coutinot, } \\
\text { J. Lopez }\end{array}$ & $\begin{array}{l}\text { P526P-15-04274, } \\
\text { VFr00_Dn }\end{array}$ \\
\hline & hordei Kurdjumov & D. noxia & France & Herault & Montpellier & 69 & 2011 & $\begin{array}{l}\text { G. Mercadier, } \\
\text { M. Roche }\end{array}$ & $\begin{array}{l}\text { P526P-15-04274, } \\
\text { VFr11_Dn }\end{array}$ \\
\hline & \multirow{2}{*}{$\begin{array}{l}\text { kurdjumovi } \\
\text { (Kurdjumov) } \\
\text { varipes (Förster) }\end{array}$} & R. padi & $\begin{array}{l}\text { Republic } \\
\text { of Georgia }\end{array}$ & Tbilisi & Satchergesi & 80 & 2000 & D. Coutinot & \multirow{2}{*}{$\begin{array}{l}\text { P526P-13-02503, } \\
\text { VGg00_Rp } \\
\text { P526P-13-02503, } \\
\text { VFr00_Rp }\end{array}$} \\
\hline & & R. padi & France & Herault & $\begin{array}{l}\text { Prades-le- } \\
\text { Lez }\end{array}$ & 107 & 2000 & $\begin{array}{l}\text { N. Ramualde, } \\
\text { D. Coutinot, } \\
\text { J. Lopez }\end{array}$ & \\
\hline
\end{tabular}


Table 2. Aphids and host plants on which parasitism by Aphelinus species was measured.

\begin{tabular}{|c|c|c|c|c|c|}
\hline \multicolumn{2}{|r|}{ Aphid } & \multicolumn{4}{|c|}{ Host plant } \\
\hline & Myzus persicae (Sulzer) & Brassicaceae & Raphanus sativus L. & Cherry Belle & radish \\
\hline & $\begin{array}{l}\text { L Acyrthosiphon pisum Harris } \\
\text { [ Aphis craccivora Koch }\end{array}$ & Fabaceae & Vicia faba L. & Windsor & fava bean \\
\hline & Aphis glycines Matsumura & & Glycine $\max (\mathrm{L})$. & Pioneer 91Y70 & soybean \\
\hline & Aphis gossypii (Glover) & Malvaceae & Gossypium hirsutum L. & SG105 & cotton \\
\hline & Aphis helianthi Monell & Asteracea & Helianthus annuus L. & - & common sunflower \\
\hline & Aphis monardae Oestlund & Laminacea & Monarda fistulosa L. & - & wild bergamot \\
\hline Aphidini & Aphis nerii Boyer de Fonscolombe & Apocynaceae & Asclepias syriaca L. & - & common milkweed \\
\hline & Aphis oestlundi Gillette & Onagraceae & Oenothera biennis L. & - & common evening-primrose \\
\hline
\end{tabular}


Table 3. Analyses of deviance for effect of aphid species on parasitism (mummies formed after $24 \mathrm{~h}$ exposure) by parasitoids in the genus Aphelinus collected from aphids on wheat, barley, and maize.

\begin{tabular}{|c|c|c|c|c|c|c|}
\hline \multirow{2}{*}{$\begin{array}{l}\text { parasitoid } \\
\text { species }\end{array}$} & \multirow[b]{2}{*}{ factor } & \multicolumn{2}{|c|}{ model } & \multicolumn{2}{|c|}{ residual } & \multirow[b]{2}{*}{$P$} \\
\hline & & df & deviance & $\mathrm{df}$ & deviance & \\
\hline \multirow[t]{3}{*}{ asychis } & collection host & 1 & 6.3 & 134 & 179.1 & 0.01 \\
\hline & aphid species & 6 & 7.4 & 128 & 171.7 & 0.28 \\
\hline & interaction & 6 & 2.7 & 122 & 169.0 & 0.85 \\
\hline albipodus & aphid species & 6 & 12.3 & 44 & 62.5 & 0.06 \\
\hline \multirow[t]{3}{*}{ atriplicis } & collection country & 1 & 8.9 & 189 & 262.9 & 0.003 \\
\hline & aphid species & 6 & 17.3 & 183 & 245.6 & 0.008 \\
\hline & interaction & 6 & 15.7 & 177 & 229.9 & 0.02 \\
\hline certus & aphid species & 6 & 48.0 & 65 & 82.6 & $<0.00001$ \\
\hline hordei & aphid species & 6 & 19.9 & 214 & 262.6 & 0.003 \\
\hline kurdjumovi & aphid species & 6 & 161.3 & 110 & 96.1 & $<0.00001$ \\
\hline varipes & aphid species & 6 & 84.5 & 116 & 139.1 & $<0.00001$ \\
\hline
\end{tabular}


Table 4. Analyses of deviance for effect of aphid species on adult emergence rate of parasitoids in the genus Aphelinus collected from aphids on wheat, barley, and maize.

\begin{tabular}{|c|c|c|c|c|c|c|}
\hline \multirow{2}{*}{$\begin{array}{l}\text { parasitoid } \\
\text { species }\end{array}$} & \multirow[b]{2}{*}{ factor } & \multicolumn{2}{|c|}{ model } & \multicolumn{2}{|c|}{ residual } & \multirow[b]{2}{*}{$P$} \\
\hline & & df & deviance & $\mathrm{df}$ & $\overline{\text { deviance }}$ & \\
\hline \multirow[t]{3}{*}{ asychis } & collection host & 1 & 0.004 & 114 & 2.8 & 0.65 \\
\hline & aphid species & 6 & 0.7 & 108 & 2.2 & $<0.00001$ \\
\hline & interaction & 6 & 0.07 & 102 & 2.1 & 0.72 \\
\hline albipodus & aphid species & 6 & 0.5 & 36 & 1.3 & 0.02 \\
\hline \multirow[t]{3}{*}{ atriplicis } & collection country & 1 & 0.2 & 172 & 7.2 & 0.02 \\
\hline & aphid species & 6 & 0.7 & 166 & 6.6 & 0.002 \\
\hline & interaction & 6 & 1.4 & 160 & 5.1 & $<0.00001$ \\
\hline certus & aphid species & 6 & 0.1 & 53 & 1.0 & 0.56 \\
\hline hordei & aphid species & 3 & 0.8 & 31 & 0.7 & $<0.00001$ \\
\hline kurdjumovi & aphid species & 5 & 0.4 & 49 & 1.8 & 0.05 \\
\hline varipes & aphid species & 6 & 1.4 & 77 & 4.0 & 0.0002 \\
\hline
\end{tabular}


Table 5. Analyses of deviance for effect of aphid species on sex ratio of parasitoids in the genus Aphelinus collected from aphids on wheat, barley, and maize.

\begin{tabular}{|c|c|c|c|c|c|c|}
\hline \multirow{3}{*}{$\begin{array}{l}\text { parasitoid } \\
\text { species } \\
\text { asychis }\end{array}$} & \multirow[b]{2}{*}{ factor } & \multicolumn{2}{|c|}{ model } & \multicolumn{2}{|c|}{ residual } & \multirow[b]{2}{*}{$P$} \\
\hline & & $\mathrm{df}$ & ance & $\mathrm{df}$ & iance & \\
\hline & collection host & 1 & 0.1 & 113 & 9.0 & 0.32 \\
\hline & aphid species & 6 & 0.2 & 107 & 8.8 & 0.83 \\
\hline & interaction & 6 & 0.6 & 101 & 8.2 & 0.26 \\
\hline albipodus & aphid species & 5 & 0.5 & 31 & 2.7 & 0.36 \\
\hline atriplicis & collection country & 1 & 0.6 & 159 & 15.6 & 0.02 \\
\hline & aphid species & 6 & 0.5 & 153 & 15.2 & 0.60 \\
\hline & interaction & 6 & 0.4 & 147 & 14.8 & 0.74 \\
\hline certus & aphid species & 5 & 0.4 & 51 & 2.9 & 0.18 \\
\hline hordei & aphid species & 1 & 0.1 & 31 & 3.3 & 0.31 \\
\hline kurdjumovi & aphid species & 4 & 1.6 & 43 & 3.9 & 0.001 \\
\hline varipes & aphid species & 5 & 2.1 & 68 & 8.0 & 0.004 \\
\hline
\end{tabular}


Table 6. Analysis of deviance for effect of aphid species on behavior of Aphelinus hordei and the aphid species it attacked.

\begin{tabular}{|c|c|c|c|c|c|c|}
\hline & \multirow[b]{3}{*}{ approached } & \multicolumn{2}{|c|}{ model } & \multicolumn{2}{|c|}{ residual } & \multirow[b]{2}{*}{$P$} \\
\hline & & $\mathrm{df}$ & eviance & $\mathrm{df}$ & deviance & \\
\hline \multirow{4}{*}{$\begin{array}{l}\text { number } \\
\text { of aphids }\end{array}$} & & 8 & 171.2 & 81 & 82.0 & $<0.00001$ \\
\hline & stung & 8 & 204.8 & 81 & 63.3 & $<0.00001$ \\
\hline & oviposited & 8 & 32.4 & 15 & 18.0 & 0.00008 \\
\hline & host-fed & 8 & 36.0 & 81 & 24.8 & 0.00002 \\
\hline \multirow{3}{*}{$\begin{array}{l}\text { handling } \\
\text { time }\end{array}$} & not host-fed & 4 & 14.5 & 33 & 39.4 & 0.006 \\
\hline & host-fed & 2 & 1.9 & 9 & 12.1 & 0.38 \\
\hline & aphid defense & 4 & 10.9 & 46 & 57.8 & 0.03 \\
\hline
\end{tabular}

